\title{
THE EVALUATION OF THE EFFECTS ON HEALTH AND ENVIRONMENT POSED BY THE GASEOUS HYDROCARBONS FROM GEOTHERMAL WATERS
}

\author{
Andrei Szollosi-Motą ${ }^{1}$, Constantin Lupu ${ }^{1}$, Maria Prodan ${ }^{1}$, Irina Nălboc ${ }^{1}$, Emilian \\ Ghicioi $^{1}$
}

${ }^{1}$ National Institute for Research and Development in Mine Safety and Protection to Explosion - INSEMEX Petrosani, 32-34 G-ral Vasile Milea Street, Postcode: 332 047, Petrosani, Hunedoara County, Romania, (40) 254541 621; (40) 254541 622; Fax: (40) 254546 277; E-mail: Web insemex@insemex.ro: http://www.insemex.ro

\begin{abstract}
Our country has significant geothermal resources, which are located mainly in the western area. The composition of geothermal water consists of solutes in the water, minerals and gases which can form complex natural solutions where can be found separated substances, dissociated and gases in unsolved phases of various concentrations, chemical combinations and physical-chemical states of great diversity.

Among the dissolved gases in the geothermal waters significant quantities of hydrocarbons in gaseous state can be found, non-dissolved in water, the most representative being the methane gas. The purpose of this study was to determine the hydrocarbons dissolved and non-dissolved in some geothermal waters, involving various physicochemical analysis methods (gas phase chromatography and detection using electrochemical sensors).

Following the analysis performed to a number of geothermal water samples the high concentration of gaseous hydrocarbons was highlighted, mainly methane (over $60 \%$ volume) in the geothermal water drill. The effects of uncontrolled methane leak in the atmosphere can have serious consequences due to the explosion hazard posed by it and can represent also an important factor in global warming, depending of the amount discharged.
\end{abstract}

Keywords: gas chromatographic analysis, geothermal, methane gas

\section{Introduction}

The main geothermal reservoirs in Romania are located in Campia de Vest as well as in the North-West, in Satu Mare, Tasnad, Acas, Marghita, Salonta.

Exploring thermal water resources of our country began in the 1960 when an extensive hydrocarbons reserves research project started, opportunity that led to the discovery of areas having real geothermal potential [1].

Geothermal reservoirs formation in our country is the result of the presence of areas with high heat flow [2]. Heat excess manifested by increased heat flow originates in sub crustal magmatic processes and occurs due to regional characteristics related to lithosphere structure. The presence of this heat flow is mainly due to the thinning of the earth's crust [3].

The presence of coal layers and oil deposits in the area Satu Mare - Oradea, is a rich source of organic matter producing liquid or gaseous hydrocarbons. Following the analysis of surface and underground drinking water, was observed that drinking water samples taken from the area mentioned above reached even 1,6 - 3,4 mg/l (Săcuieni area, located $60 \mathrm{~km}$ from Acas). Thermal waters from Săcuieni thermal aquifer, presented levels of hydrocarbons reaching up to $32,27-41,18 \mathrm{mg} / \mathrm{l}$. 
Methane is most often generated and stored in the sedimentary rocks associated with layers of coal or oil or gases. Methane can be transported by groundwater in dissolved or pure gaseous state [8]. Methane in groundwater is not explosive, but when water containing dissolved methane comes into contact with air, it is quickly released to the atmosphere.

Henry's Law is one of the main laws of gases and was enunciated by William Henry in 1803. It states: "At a constant temperature, the amount of a given gas that dissolves in a given type and volume of liquid is directly proportional to the partial pressure of that gas in equilibrium with that liquid". Gases dissolve in liquids to which they come in contact with. If temperature increases, the amount of dissolved gas, at saturation, decreases and vice versa. The amount of gas dissolved in liquid at saturation is dependent on both liquid type and gas type.

Gases dissolve in liquid until the liquid become saturated with dissolved gas. Saturation of a liquid with dissolved gas corresponds to the maximum amount of gas that can be absorbed by liquid at constant temperature and pressure. The dissolved gas partial pressure increases in time due to the increased quantity of dissolved gas in the liquid [1]. At saturation, partial pressure of dissolved gas, reaches the value of the above the liquid gas pressure. When the above liquid gas is not pure, but is a mixture of gases, each component gas will dissolve and the pressure grow curves will depend on the partial pressures of the gases that make up the mixture. When the external pressure decreases, the partial pressure of dissolved gas becomes higher than the pressure of the gas that is in contact with the liquid. In this case, it is said that the liquid is in a state of oversaturation [4]. Oversaturation is an unstable state and there is a limit value of the ratio of dissolved gas pressure and ambient pressure, beyond which the unstable equilibrium is broken, appearing the phenomenon of release with emergence of bubbles. This limit is called the oversaturation critical ratio. In this paper were performed analyses in order to establish the content of hydrocarbons that are dissolved in the geothermal waters. The analyses were performed at ambient temperature and by conditioning the samples at $60^{\circ} \mathrm{C}$.

\section{Experimental}

Finding the hydrocarbons concentration in samples of geothermal water was carried out in the laboratory by gas-chromatographic method with a Perkin Elmer Clarus 500 gas-chromatograph configured for the analysis of saturated and unsaturated hydrocarbons.

The collected samples of water (Fig. no. 1) were also analyzed at ambient temperature and after conditioning at $60^{\circ} \mathrm{C}$. In this regard, from inside the vessel an amount of air was collected and analyzed, before and after conditioning. From the 1-liter container of sampled water, $500 \mathrm{ml}$ was transferred into a laboratory wash bottle. From the plastic container in which the sample was collected, after stirring, an amount of air was collected, which was analyzed by gas chromatography. The laboratory wash bottle, after sealing, was conditioned for 1 hour at $60^{\circ} \mathrm{C}$, to release the undissolved gases in the water. After conditioning, an amount of air was sampled from the wash bottle, which was analyzed by gas chromatography.

A series of direct measurements were performed by using the EX TEC 660 device, to track the concentration of methane released. The direct measurements were performed at the sampling location, in the extraction pipe and in the laboratory from the collected samples. 


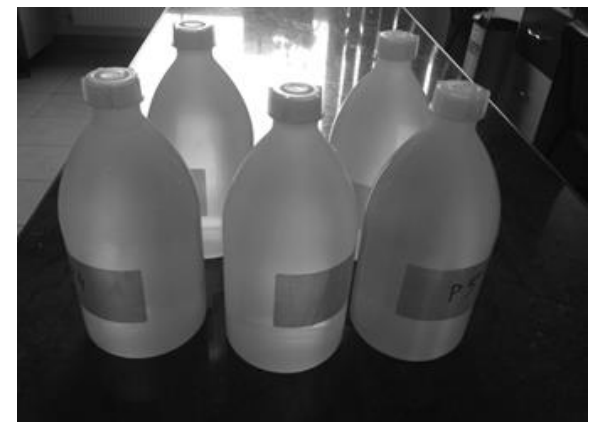

Fig. no.1 - Collected samples of geothermal water

\section{Results and Discussion}

The concentration of the methane measured at the place of geothermal water discharge performed with the EX TECH portable detector was $64 \%$ vol. In the figure no. 2 there can be seen the measurement technique in the pipe of the geothermal water.

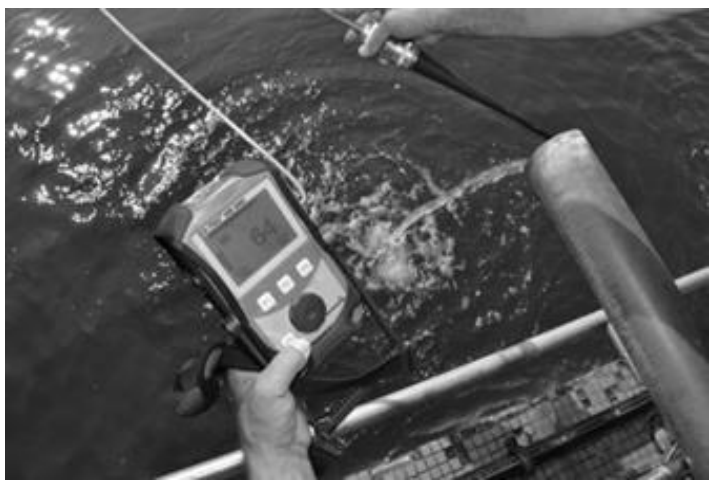

Fig. no. 2 - Measuring the concentration of methane gas that accompanies geothermal water

Following the instrumental measurements, in the laboratory, from the geothermal water collected, in sample no. 1 , was obtained a concentration of $2,4 \%$ volume methane, as it can be seen in the figure no. 3 .

The gas-chromatographic analysis performed on the sample no. 1, at ambient temperature confirmed the direct analysis as it can be seen in the table 1 , where are given also the concentration of the identified hydrocarbons.

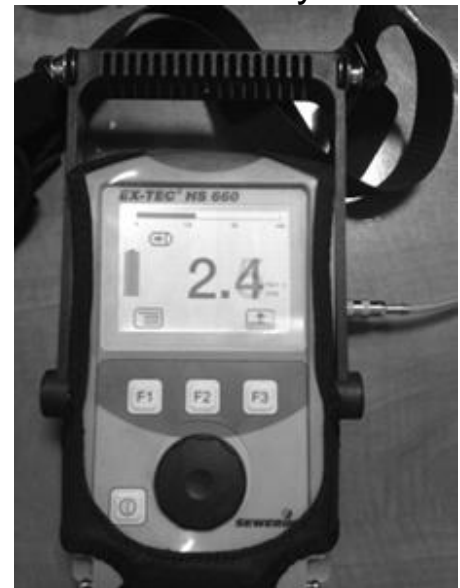

Fig. no. 3- Gas concentration instrumentally measured 
Table 1 - Chemical composition of air sampled from the thermal water container

\begin{tabular}{|c|c|}
\hline Measured gas & Concentration \\
\hline Carbon dioxide & $2,54 \%$ vol. \\
\hline Methane & $2,36 \%$ vol. \\
\hline Ethan & $82 \mathrm{ppm}$ \\
\hline Propane & $105 \mathrm{ppm}$ \\
\hline Iso-butane & $43 \mathrm{ppm}$ \\
\hline N-butane & $13 \mathrm{ppm}$ \\
\hline
\end{tabular}

In the analyzed sample, through gas chromatographic analysis and related to the volume of air $(500 \mathrm{ml})$ and water $(500 \mathrm{ml})$, at ambient temperature $\left(24^{\circ} \mathrm{C}\right)$ the following amounts of gases, relative to the volume of water were determined:

- Carbon dioxide: $49,6 \mathrm{mg} / \mathrm{l}$;

- Methane: 16,8 mg/l;

- Ethane: $0,1 \mathrm{mg} / \mathrm{l}$;

- Propane 0,21 mg/l;

- Iso-butane: 0,11 mg/l;

- N-butane: 0,033 mg/l.

In order to determine the amount of gases from the geothermal water, sample no. 2 was conditioned at $60^{\circ} \mathrm{C}$, and the results are given in the table no. 2 .

Table 2 - Gas concentrations measurement results

\begin{tabular}{|l|l|}
\hline The sample at ambient $24^{\circ} \mathrm{C}$ & The sample conditioned at $60^{\circ} \mathrm{C}$ \\
\hline Carbon dioxide: $0,1 \%$ & Carbon dioxide: $1,63 \%$ \\
\hline Methane: $0,0164 \%$ & Methane: $0,18 \%$ \\
\hline Ethane: $0,58 \mathrm{ppm}$ & Ethane: $2,41 \mathrm{ppm}$ \\
\hline
\end{tabular}

When conditioning the thermal water sample at a temperature of $60^{\circ} \mathrm{C}$, some of the gases dissolved in water passes in the mixed air-gas area, above the liquid, in accordance with Henry's law, which explains the increase in concentration measured in the conditioned sample, compared to the sample analyzed at ambient temperature of $24^{\circ} \mathrm{C}$;

Methane solubility in water decreases with increasing temperature. When water containing dissolved methane comes into contact with air [5], methane is rapidly released into the atmosphere, more so, when this happens at a high temperature, favors its release.

The presence of hydrocarbons in the geothermal waters, especially the presence of methane in high concentration poses an explosion hazard but also an important factor in global warming due to the amount discharged.

Methane - air explosion are the most frequent accidental incidents. Methane is one of the most studied fuels, due to its natural occurrence. Its oxidation with gaseous oxygen from air, either as such or mixed with other fuels, is an exothermic process frequently used as a source of heat or energy. At the same time, within some concentration limits, the methane/air mixtures are hazardous systems, being able to sustain explosions, either as deflagrations or as detonations, thus requiring severe safety norms to protect the people and the environment. The flammability limits of $\mathrm{CH}_{4}$ in air range between 5 and $15 \%$ in normal conditions [6,7]. As it can be seen, the high concentration measured in the pipe where the geothermal waters are discharged is few time bigger that the 
flammability limit. This means that, when dealing with this kind of waters, it is mandatory to provide the required safety rules.

Some gases in Earth's atmosphere acts like a greenhouse walls - capture and retain the sun's heat, so it is not released back into space. Many of them are naturally present in the atmosphere [6], but human activity led to increased concentrations of some of them, particularly:

- Carbon dioxide $\left(\mathrm{CO}_{2}\right)$

- Methane

- Fluorinated gases

$\mathrm{CO}_{2}$ is the greenhouse effect gas [8] most often generated by human activities, being responsible in proportion of $63 \%$ of global warming caused by man. Its concentration in the atmosphere is now $40 \%$ higher than in the pre-industrial era.

Other greenhouse effect gases are emitted into the atmosphere in smaller quantities, but capture and retain heat more efficiently than the $\mathrm{CO}_{2}$ and in some cases are by thousands of times more powerful. Methane contributes by $19 \%$ to global warming caused by man, and nitrous oxide by $6 \%$.

\section{Conclusions}

Geothermal water is a very important resource for our country, both in terms of using geothermal energy as well as tourism. These waters, along with dissolved salts also contain significant amounts of dissolved gases, such as carbon dioxide and hydrocarbons.

From the hydrocarbons found in the analyzed geothermal waters the major component is methane. It accompanies geothermal waters both in dissolved state and in nondissolved gaseous state, the water column being discontinuous.

Thus, following measurements taken, significant concentrations of methane were found, compassed between $0,016 \%$ and $2,4 \%$ for dissolved methane and $64 \%$ for non-dissolved methane.

Thus it can be concluded that there is a need to eliminate the methane gas and related hydrocarbons from the geothermal waters by degassing, this being particularly important because of the danger of methane accumulation and the formation of explosive atmospheres, danger that may occur in enclosed spaces and also in terms of global warming, methane contributing to global warming by $19 \%$.

Methane solubility in water decreases with increasing temperature. When water containing dissolved methane comes into contact with air, it is rapidly released into the atmosphere, more so, when this happens at a high temperature favoring its release.

\section{References}

[1] Holm A., D. Jennejohn, L. Blodgett, (2012), Geothermal Energy and Greenhouse Gas Emissions, Report of Geothermal Energy Asociation.

[2] Rosca, M., (1999), Geotermalism and geothermal plants, Editura Universităii din Oradea, Oradea.

[3] Balan, M., (2007), Renewable energies, UT PRES Publishing House, Cluj Napoca, 2007.

[4] Rosca, M., 2007, Geothermal energy use in Romania, Renexpo International Conference, Budapest, 20 Apr. 2007. 
[5] David I. Norman and Joseph N. Moore (1999), Methane and excess $\mathrm{N}_{2}$ and Ar in geothermal fluid inclusions, Proceedings Twenty Third Workshop on Geothermal Reservoir Engineering, Standford University, California.

[6] Cashdollar K.L., Zlochower I.A., Green G.M., Thomas R.A., Hertzberg M., (2000), Flammability of methane, propane, and hydrogen gases, J. Loss Prevent. Proc., 13, 327-340. [7] D. Oancea, M. Prodan și D. Razus, (2016), Investigation of laminar flame propagation of the most hazardous confined methane/air mixture using pressure-time records in a small vessel," New Frontier Chemistry, vol. 1, pp. 64-72.

[8]. * Study on evaluating the current potential of renewable energy sources in Romania, http://www.minind.ro/domenii_sectoare/energie/studii/potential_energetic.pdf 